\title{
Effect of Pruning Intensities on the Performance of Fruit Plants under Mid-Hill Condition of Eastern Himalayas: Case Study on Guava
}

\author{
Rupankar Bhagawati ${ }^{1}$, Kaushik Bhagawati ${ }^{{ }^{*}}$, Vijay Kumar Choudhary ${ }^{2}$, \\ Deep Jyoti Rajkhowa ${ }^{3}$ and Rupjyoti Sharma ${ }^{3}$ \\ ${ }^{1}$ ICAR Research Complex for NEH Region, Arunachal Pradesh Centre, Basar-791101 \\ ${ }^{2}$ ICAR-National Institute of Biotic-Stress Management, Baronda, Raipur- 493225 \\ ${ }^{3}$ ICAR Research Complex for NEH Region, Umiam, Meghalaya-793103 \\ *Corresponding author: kaushik.iasri@gmail.com
}

Keywords: Pruning, Fruit quality, Canopy Management, Guava

\begin{abstract}
Current study was undertaken to highlight the effect of pruning on improving vigor of old orchards and increasing performance in terms of fruit yield and quality under water and nutrient stressed condition of mid hills of Eastern Himalaya. Guava was taken for the case study and all the physical and chemical properties of the fruits and other attributes of plant were evaluated using standard methods under three pruning intensities (light, moderate and severe) and no pruning. The emergence of bud was earliest in severe pruning, number of buds per shoot was highest with light pruning and cumulative lengths of new shoots were found to be highest in severe pruning. Fruit yield, size and weight were found to increase with pruning intensities and lowest in case of no pruning. Regarding chemical properties, total soluble solids and total sugar found to increase with enhanced pruning severity and least in case of no pruning. Acidity was found to be highest with no pruning and decrease with increase in pruning intensities. Overall pruning found to have rejuvenating impact on aged trees due to better light interception leading to better photosynthetic rate, better nutrient and water supply with reduced canopy and better quality yields.
\end{abstract}

\section{INTRODUCTION}

The research suggested that for a shoot tip to be active, it must be able to export auxin into the main stem [1]. It cannot be established if substantial amounts of auxin already exist in the main stem. The mechanism leads to competition among the shoot tips both above and below influencing each other's growth. This allows the strongest branches to grow most vigorously and dominate other mostly because it was there first, rather than because of its position at the apex of the plant. The main growing shoot of a plant can inhibit the growth of the shoots below and thus timely pruning encourage growth of branches. Pruning is a horticultural and silvicultural practice involving the selective removal of parts of plants, such as branches, buds, or roots. Especially for horticultural fruit trees, the major reason behind pruning include improving plant health, reducing risk from falling branches, lowering canopy of high density planting and increasing the yield or quality of fruits. Pruning before the growth stage of plant reduce the number of leaves produced in coming year which result in less requirement of nutrients and water. The strong root system below provides sufficient nutrients for rapid growth of above parts especially those parts that were severely pruned. In general pruning rejuvenates the plants and increases its performance under reduced nutrition and water. As cultural practice it removes weak and diseased part of plant and also increases landscaping of the orchard. Flowers and fruits of the pruned plants show comparatively less drop [2]. Gorakh Singh (2001) [3] indicated that canopy management is vital to control tree growth patterns, tree shape and maintaining high fruit production of desired size and quality. Pruning levels under high density planting is vital for building strong frame work of the trees in early years and for maintaining vigor, yield, productivity and quality of fruits in later years. Pruning intensities found to have positive correlation with fruit diameter in pomegranate [4]. In mango, the number of fruited panicles was found to be more in moderately pruned trees compared to non-pruned one [5]. In some experiment it was found that size of fruits improved with pruning intensities [6]. They also observed 
that the pruning affect the fruit quality (TSS, acidity etc). Pruning intensity also affects the fruit weight under high density planting [7]. Although a high number of fruit bads per plant is desirable to achieve higher yield per unit area, the competition for assimilates among fruits can reduce whole canopy leaf area, which leads to a lower fruit quality [8]. Thus pruning and its intensity is very crucial for proper orchard management and performance of fruit trees.

Keeping above facts under consideration, the study was undertaken to evaluate the effect of pruning intensities on the performance of old Guava orchard under water stressed mid-hill condition of Arunachal Pradesh. Guava (Psidium guajava L.) is regarded as 'poor man's fruit' and 'Apple of tropics', belongs to family Myrtaceace and is most widely cultivated fruits in tropical and subtropical climate. It is known for its comparatively higher productivity, hardiness, adaptability and nutritive value. Guava responds well to pruning as it bears on current season's growth and flowers appear in the axils of new leaves [9]. Among the various cultural practices in guava cultivation, pruning was found to have maximum influence on the vigor, productivity and quality of fruits [10]. High density planting shows significant decline in yield and quality after 8-9 years of fruiting owing to intermingling of branches, poor light interception, poor photosynthetic rate, high relative humidity and pest and disease incidence [11,7].

\section{MATERIALS AND METHODS}

\section{Study Site}

The research was done in ICAR Research Farm Gori, Basar, which is located at $27^{\circ} 58.590^{\prime}$ $\mathrm{N}$ latitude and $94^{\circ} 41.120^{\prime} \mathrm{E}$ longitude at an altitude of $660 \mathrm{~m} \mathrm{msl}$. The experiment was carried out in 10-12 years old Guava Orchard during 2011-2013.

Experimental Design and Procedures

The experiment was done on guava plants grown at spacing of $2.5 \times 2.5 \mathrm{~m}$ spacing under high density planting system. The experiment was laid out in factorial RBD with 4 treatments replicated twice with three trees per replication. Observations recorded were fruit diameter, average weight, yield and quality. Tree under investigation were subjected to the following pruning treatments according to [12]: Light, Moderate and Severe.

\section{Fruit Physical Properties}

Fruits were samples separately from each tree at full maturity. Weights of five randomly selected fruits from five randomly selected trees of each treatment were taken. Fruit diameter was calculated using vernier calipers.

\section{Fruit Chemical Properties}

The Total Soluble Solids (TSS) was determined with the help of Bausch and Lomb Refractometer in terms of degree Brix and values were corrected at $20^{\circ} \mathrm{C}$ [13]. Total sugar contents were determined using methods suggested by Ranganna, 1986 [13]. Ascorbic acid was determined using 2, 6- dichlorophenol indophenols solutions and oxalic acid as a substrate and expressed as $\mathrm{mg} / 100 \mathrm{gm}$. Acidity was calculated using standard counter-active reagent, e.g. an alkali $(\mathrm{NaOH})$.

\section{RESULTS AND DISCUSSION}

Pruning intensity found to have significant influence on the number of days taken to first vegetative bud appearance with early bud appears in sever pruning (3.98 days) followed by moderate (4.44 days) and light (5.01 days). The result was found to be in accordance with the findings of pervious researchers $[14,15]$. This may be attributed to relatively more nutrient available to vegetative bud [16] and also may be due to more light interception that induces early sprouting of vegetative buds. Also it was observed that all the pruning treatments result in early vegetative buds compared to no pruning. This may be due to removal of apical dominance, release of buds from correlative inhibition and efficient transfer system [17]. 
Table 1. Variation of plant physical and yield attributes with pruning intensities. The value within the column with same subscript are not significant while with different value vary significantly at $\mathrm{p}<0.05$. Statistical analysis was done with ANOVA followed by DMRT at 95\% CI using SPSS software.

\begin{tabular}{lcccccrr}
\hline Treatments & $\begin{array}{c}1^{\text {st }} \text { bud } \\
\text { appearance } \\
(\text { Days })\end{array}$ & $\begin{array}{c}\text { Number of } \\
\text { Shoots per } \\
\text { pruned shoots }\end{array}$ & $\begin{array}{c}\text { Cumulative } \\
\text { length } \\
(\mathrm{cm})\end{array}$ & $\begin{array}{c}\text { Fruit } \\
\text { Diameter } \\
(\mathrm{cm})\end{array}$ & $\begin{array}{c}\text { Fruit } \\
\text { Weight } \\
(\text { gram })\end{array}$ & \multicolumn{2}{c}{ Yield } \\
\hline No Pruning & $5.45^{\mathrm{a}}$ & $4.10^{\mathrm{a}}$ & $20.33^{\mathrm{a}}$ & $5.89^{\mathrm{a}}$ & $221.3^{\mathrm{a}}$ & $5.98^{\mathrm{a}}$ & \\
Light & $5.01^{\mathrm{a}}$ & $4.81^{\mathrm{a}}$ & $25.12^{\mathrm{b}}$ & $6.15^{\mathrm{b}}$ & $245.6^{\mathrm{a}}$ & $8.70^{\mathrm{b}}$ & $13.98^{\mathrm{b}}$ \\
Moderate & $4.44^{\mathrm{b}}$ & $5.86^{\mathrm{b}}$ & $27.11^{\mathrm{b}}$ & $6.45^{\mathrm{bc}}$ & $298.1^{\mathrm{b}}$ & $9.60^{\mathrm{b}}$ & $15.31^{\mathrm{b}}$ \\
Severe & $3.98^{\mathrm{b}}$ & $7.10^{\mathrm{c}}$ & $32.81^{\mathrm{c}}$ & $7.15^{\mathrm{c}}$ & $300.2^{\mathrm{b}}$ & $11.66^{\mathrm{c}}$ & $18.16^{\mathrm{c}}$ \\
Mean & 4.72 & 5.47 & 26.34 & 6.41 & 266.30 & 8.99 & 14.12 \\
$\mathrm{SE} \pm$ & 0.37 & 0.75 & 2.98 & 0.31 & 22.64 & 1.36 & 2.21 \\
\hline
\end{tabular}

Table 2. Variation of plant chemical properties with pruning intensities. The value within the column with same subscript are not significant while with different value vary significantly at $\mathrm{p}<0.05$.

\begin{tabular}{lrrr}
\hline Treatments & TSS ( ${ }^{\circ}$ Brix $)$ & $\begin{array}{c}\text { Total Sugar } \\
(\%)\end{array}$ & Acidity (\%) \\
\hline No Pruning & $8.43^{\mathrm{a}}$ & $7.56^{\mathrm{a}}$ & $0.241^{\mathrm{a}}$ \\
Light & $9.08^{\mathrm{b}}$ & $8.73^{\mathrm{b}}$ & $0.211^{\mathrm{bc}}$ \\
Moderate & $9.82^{\mathrm{c}}$ & $8.81^{\mathrm{bc}}$ & $0.201^{\mathrm{bc}}$ \\
Severe & $10.1^{\mathrm{c}}$ & $9.12^{\mathrm{c}}$ & $0.197^{\mathrm{c}}$ \\
Mean & 9.36 & 8.56 & 0.21 \\
SE \pm & 0.43 & 0.40 & 0.01 \\
\hline
\end{tabular}

Among the treatments it was observed that maximum shoots per pruned shoot was recorded in case of light pruning (7.10) followed by moderate (5.86) and severe (4.81) as shown in Table 1. This indicate that severely pruned shoot have fewer number of shoots per pruned shoot, which agree with the earlier findings [18]. This might be due to less number of vegetative buds in severely pruned shoot. While the new shoots per shoot was lowest in shoots without pruning (Table 1).

Cumulative lengths of new shoots in case of all pruning intensities were found to be significantly greater than those without pruning. Highest cumulative length of new shoots was observed in case of severe pruning $(32.81 \mathrm{~cm})$ followed by moderate $(27.11 \mathrm{~cm})$ and light $(25.12$ $\mathrm{cm})$ as depicted in Table 1 . The finding is in agreement with previous finding with pomegranate [19] and with apple [18]. Also, Shaban \& Haseeb (2009) [20] also observed that length of new shoots of guava was found to be highest in severely pruned shoots. This may be attributed to relatively less numbers of shoots and availability of more nutrients per shoots under identical condition.

Pruning found to have significant impact on increase in the fruit diameter, average fruit weight and fruit yield compared to no pruning (Table 1). The result indicate that the fruit diameter at the time of harvest was maximum with severe pruning $(7.15 \mathrm{~cm})$ which was significantly higher $(p<0.05)$ to that of moderate pruning $(6.45 \mathrm{~cm})$ and light pruning $(6.15 \mathrm{~cm})$. The observation agrees with previous findings in ber and pomegranate $[16,4]$. Also average fruit weight was observed in case of severe pruning (300.2 g) followed by moderate $(298.1 \mathrm{~g})$ and light $(245.6 \mathrm{~g})$. The fruit weights in all pruning treatment were found to be higher than that without pruning (Table 1.). The maximum fruit weight was observed earlier by Shaikh \& Hulmani (1993) [21] in guava, Bhanu Pratap et al (2009) [6] in mango and Syamal \& Rajput (1989) [16] in ber. This may be due to more nutrient supply to less number of fruits in case of severe pruning [22].

During the experiment the fruit yield was found to be highest in case of severe pruning (11.66 $\mathrm{kg}$ tree $\left.^{-1} ; 18.16 \mathrm{t} \mathrm{ha}^{-1}\right)$ followed by light pruning $\left(9.60 \mathrm{~kg} \mathrm{tree}^{-1} ; 15.31 \mathrm{t} \mathrm{ha}^{-1}\right)$ and moderate $(8.70 \mathrm{~kg}$ 
tree $\left.{ }^{-1} ; 13.98 \mathrm{tha}^{-1}\right)$. The yields were found to be higher in all cases over that of no pruning $(5.98 \mathrm{~kg}$ tree $^{-1} ; 9.01 \mathrm{t} \mathrm{ha}^{-1}$ ) as depicted in Table 1. Earlier study on guava also found higher fruit yield per tree in case of severe pruning [23].

Regarding the chemical properties, TSS was highest with severe pruning $\left(10.1^{\circ}\right.$ Brix $)$ followed by moderate $\left(9.82{ }^{\circ} \mathrm{Brix}\right)$ and light $\left(9.08{ }^{\circ} \mathrm{Brix}\right)$ shown in Table 2 . The TSS values in all pruning treatments were higher than that with no pruning. Total sugar was recorded to be highest in severe pruning $(9.12 \%)$ followed by moderate $(8.81 \%)$ and light $(8.73 \%)$. The total sugar content in all the pruning intensities were found to be higher than with no pruning $(7.89 \%)$. While during the experiment the acidity was found to be highest in that with no pruning $(0.241 \%)$. The acidity shows following order no pruning $>$ light pruning $>$ moderate pruning $>$ severe pruning (Table 2). Severe pruning increased TSS and reducing sugar in fruits. The increase in TSS and total sugar content was observed with increasing pruning intensities in litchi and peach [24,25]. Improved soluble solid content and sugar was found to be correlated with increase light intensity [26]. The increased rate of photosynthesis due to more light penetration into interior tree canopy increased the soluble solids in fruits of pruned trees. The decrease in acidity was in accordance with the earlier findings [27,28]. This may be attributed to deposition of higher quantum of acid that is synthesized in leaves in fruits during the development [29].

The yield of fruit plants especially guava improves with pruning [30]. Beside all these benefits of pruning, pruning was also found to have reduction of total canopy water loss (transpiration) and consequently improve water status [31]. Summarizing the results, the light becomes a limiting factor in crowded groves and pruning improves light access. It facilitates supply of adequate nutrients to reduced plant parts for their proper growth and development. Thus, Pruning with appropriate intensity, not only regulate the canopy size but also leads to better fruit quality and yield through better exposure of branches and fruits [32]. Also, pruning requirement is variety and crop specific in fruit plants that depends on growth behavior [33], so standardization of pruning is essential on location specific manner for harnessing potential yield and quality under give environmental conditions. The current study reiterated the importance of pruning especially in water and nutrient stressed hill conditions with the case study on guava.

\section{References}

[1] University of York. 2009. "Explaining Why Pruning Encourages Plants To Thrive." ScienceDaily. ScienceDaily, 23 September 2009. www.sciencedaily.com /releases/2009/09/090922095705.htm

[2] Tahir F.M., \& Kamran Hamid. (2002). Studies of Physicochemical Changes due to Fruit Thinning in Guava (Psidium guajava L.). OnLine Journal of Biological Sciences, 2(11), 744-745.

[3] Gorakh Singh. (2001). High density planting in guava. Annual Report, Central Institute of Subtropical Horticulture, Lucknow

[4] Sheikh, M.K., \& Rao, M.M. (2002). Effect of pruning and fruit load on yield and quality in pomegranate (Punica granatum L.) Var. Ganesh. Karnataka Journal of Agricultural Sciences, 15: 3, 549-555

[5] Sharma, R.R. and Singh, R. (2006). Pruning intensity modifies canopy micro-climate and influences sex ratio, malformation incidence and development of fruited panicles in 'Amrapali' mango (Mangifera indica L.). Scientia Horticulturae 109: 118-22

[6] Bhanu Pratap, Singh, S.K, Singh, H.K, Gaurav, S.S., \& Shashi Bala. (2009). Effect of pruning on physico-chemical properties of mango cv. Amrapali under high density orcharding. Annals of Horticulture, 2(1), 62-64 
[7] Singh, Sanjay Kumar, Singh, S.K., \& Sharma, R.R. (2010). Pruning alters fruit quality of mango cultivars (Mangifera indica L.) under high density planting. Journal of Tropical Agriculture, 48 (1-2), 55-57

[8] Léchaudel, M., Génard, M., Lescourret, F., Urban, L., \& Jannoyer, M. (2005) Modelling effects of weather and source-sink relationships on mango fruit growth. Tree Physio, 25, 583-597

[9] Lakpathi, G., Rajkumar, M., \& Chandrasekhar, R. (2013). Effect of Pruning Intensities and Fruit load on Growth, Yield and Quality of Guava (Psidium guajava L.) cv. Allahabad Safeda under High Density Planting. International Journal of Current Research, 5(12), 4083-4083

[10] Gadgil, D.R., \& Gadgil V.R. (1933). A survey of the marketing of fruit in Poona. Gokhale Inst. Politics and Economics Publi. : 3

[11] Lal, B., \& Mishra, D. (2007). Effect of pruning on growth and bearing behavior of mango cv. Chausa. Indian Journal of Horticulture, 64(3), 268-270

[12] Strik, B., Buller, G., \& Hellman, E. (2003). Pruning severity affects yield, berry weight, and hand harvest efficiency of highbush blueberry. Hortscience. 38, 195-199

[13] Ranganna, S. (1986). Handhook of Analysis and Quality control for Fruit and Vegetable Products. Tata McGrawHills publishing Company Limited, New Delhi, India, 1111p

[14] Jadhav, B.J, Mahurkar, V.K., \& Kale, V.S. (2002). Effect of time and severity of pruning on growth and yield of guava (Psidium guajava L.) cv. Sardar. Orissa Journal of Horticulture, 30(2), 83-86

[15] Suleman, Mohammed, Sharma, J.R, Ranjeet Kumar, Gupta, R.B., \& Sultan Singh. (2006). Effect of pruning on growth and cropping pattern in guava cv. Lucknow-49. Haryana Journal of Horticultural Sciences, 35(3/4), 211-212

[16] Syamal, M.M., \& Rajput, C.B.S. (1989). Effect of pruning on growth, fruiting and quality of ber (Zizyphus mauritiana Lamk.). Indian Journal of Horticulture, 46(3), 364-367

[17] Mika, A. (1986). Physiological responces of fruit trees to pruning. In: Horticulture Review (ed) J. Janik. Vol 8, AVI Publishing House, West Port pp 337-378

[18] Gardner, V.R, Bradford, C.F., \& Hooker, H.D. (1922). The fundamentals of fruit production. pp 408-418. McGraw Hill, New York

[19] Balasubramanyam, S, Anbu, S, Bangarusamy, U., \& Chokalingam, P. (1997). Effect of pruning and training on growth, yield and quality of pomegranate in black soil under rainfed conditions. South Indian Horticulture, 45(5and6), 271-273

[20] Shaban, A.E.A., \& Haseeb, G.M.M. (2009). Effect of Pruning Severity and Spraying some Chemical Substances on Growth and Fruiting of Guava Trees. American-Eurasian journal of Agriculture and Environmental Science, 5 (6), 825-831

[21] Shaikh, M.K., \& Hulamani, N.C. (1993). Effect of severity of pruning on flowering and fruiting of guava (Psidium guajava L.) cultivar Navalur. Progressive Horticulture, 25(3-4), $157-160$

[22] Bajpai, P.N, Shukla, H.S., \& Chathurvedi, A.M. (1973). Effect of pruning on growth, yield and quality of guava (Psidium guajava L.) cv. Allahabad Safeda. Progressive Horticulture, 5(1), 73-79

[23] Satya Prakash, Virendra Kumar, Saroj, P.L., \& Sirohi, S.C. (2012). Response of yield and quality of winter guava to severity of summer pruning. Indian Journal of Horticulture, 69(2), 173-176 
[24] Kaundal, G.S., Singh, S., Kanwar, G.S., \& Chanan, Y.R. (2002). Effect of pruning techniques on growth, production, quality and nutrient status of peach cv. Pratab. Journal Research PAU, 39(3), 362-367

[25] Hossani, G., \& Razaee, R. (2007). Effect of training system and rate of pruning on yield and quality of peach fruit. Journal of Agricultural Sciences (Tabriz), 17(1), 31-38

[26] Sites, J.W., \& Reitz, H.J. (1948). The variation in individual Valencia Orange from differences locations of the tree as a guide to sampling methods and sport picking for quality soluble solids in the Juice. Proc. American Soc. Hort. Sci., 54, 1-10

[27] Sehrawat, S.K., Daulta, B.S., Dahiya, D.S., \& Bharadwaj, R. (1998). Effect of pruning on growth, yield and fruit quality in grapes (Vitis vinifera L.) cv. Thompson Seedless. International Journal of Tropical Agrictulure, 16, 185-188

[28] Somkuwar, R.G., \& Ramteke, S.D. (2007). Effect of bunch retention, quality and yield in Sharad Seedless. Annual Report 2006-07, National Research Centre for Grapes, Pune, p-20

[29] Porika, H., Jagadeesha, M., \& Suchithra, M. (2015). Effect of pruning severity on quality of grapes cv. Red Globe for summer season. Advances in Crop Science and Technology, S1:004. doi: 10.4172/2329-8863.S1-004

[30] Lal, S. (1983). Effect of pruning on crop regulation in guava (Psidium guajava L.) cv. Lucknow-49. Progressive Horticulture, 7(3), 60-62

[31] Li, K.T., Lakso, A., \& Piccioni, R. (2001). Summer Pruning: The Good, The Bad and the Ugly. New York Fruit Q, 7(2), 6-9

[32] Rao, V.N.M., \& Shanmugavelu, K.G. (1975). Mango responds to pruning. Indian Hort., 20(3), 5-6

[33] Senthilkumar, S., Vijayakumar, R.M., Soorianathasundaram, K., \& Durga Devi, D. 2015. Effect of Pruning Severity on Vegetative, Physiological, Yield and Quality Attributes in Grape (Vitis vinifera L.): A Review. Current Agricultural Research Journal, 3(1), $42-54$. 